Supporting Information

\title{
A Novel Strategy to Fabricate Cation-crosslinked Graphene Oxide Membrane with High Aqueous Stability and High Separation Performance
}

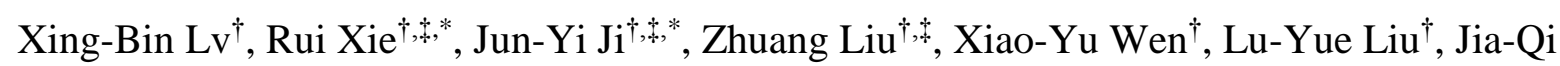
$\mathrm{Hu}^{\dagger}$, Xiao-Jie Ju ${ }^{\dagger, \dagger}$, Wei Wang ${ }^{\dagger, \dagger}$, Liang-Yin Chu ${ }^{\dagger, \dagger}$

${ }_{\dagger}^{\dagger}$ School of Chemical Engineering, Sichuan University, Chengdu 610065, Sichuan, P. R. China

${ }^{\ddagger}$ State Key Laboratory of Polymer Materials Engineering, Sichuan University, Chengdu 610065, Sichuan, P. R. China

*Corresponding Authors. E-mail: xierui@scu.edu.cn (R. X.), junyiji@scu.edu.cn (J.-Y. J.) 

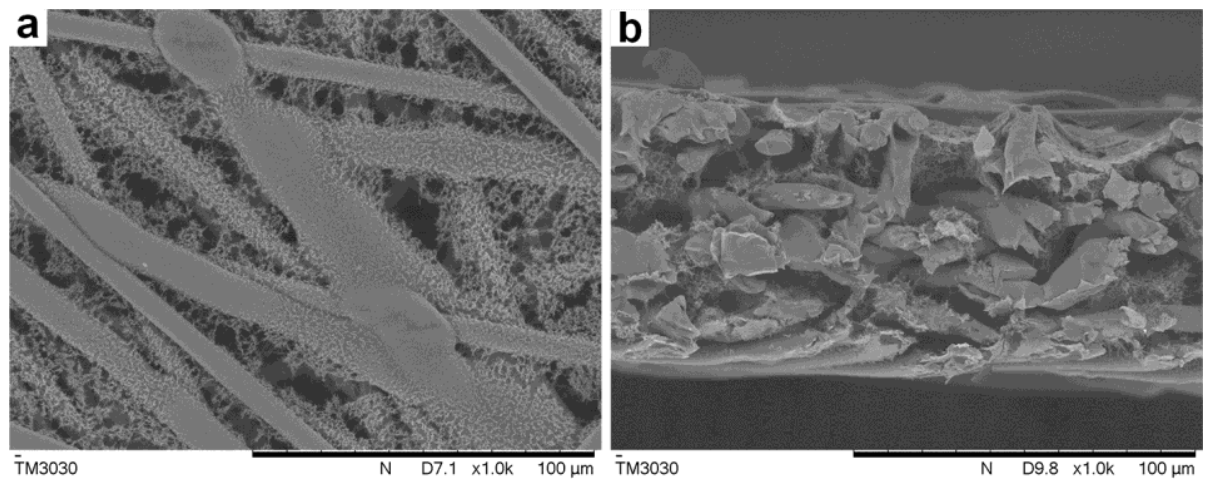

Figure S1. SEM images of surface (a) and cross-sectional (b) views of the CN-CA substrate membrane. Scale bars are $100 \mu \mathrm{m}$.

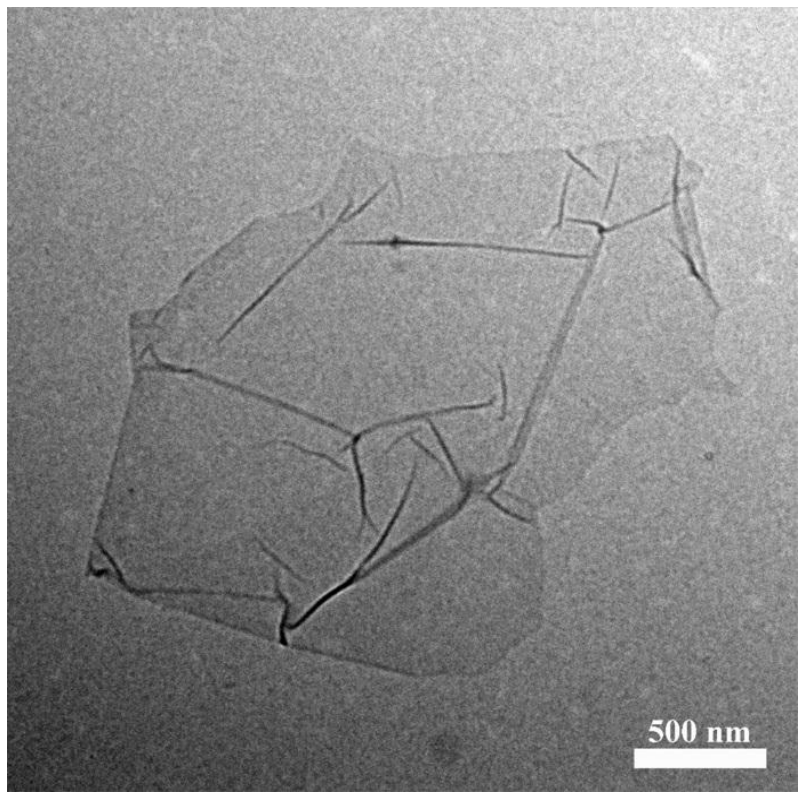

Figure S2. TEM image of GO nanosheet. 

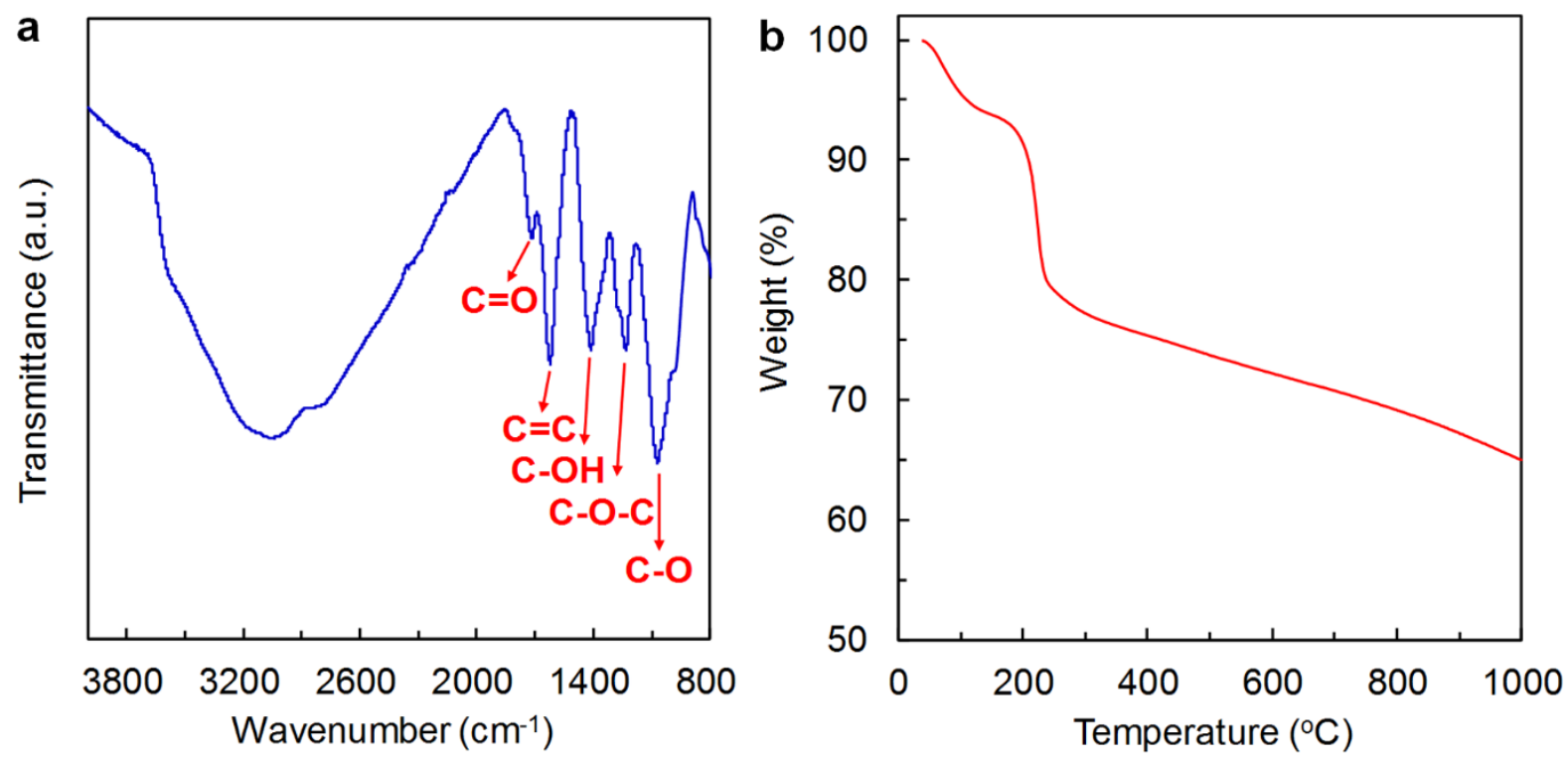

Figure S3. FT-IR spectrum (a) and TGA curve (b) of GO nanosheets.
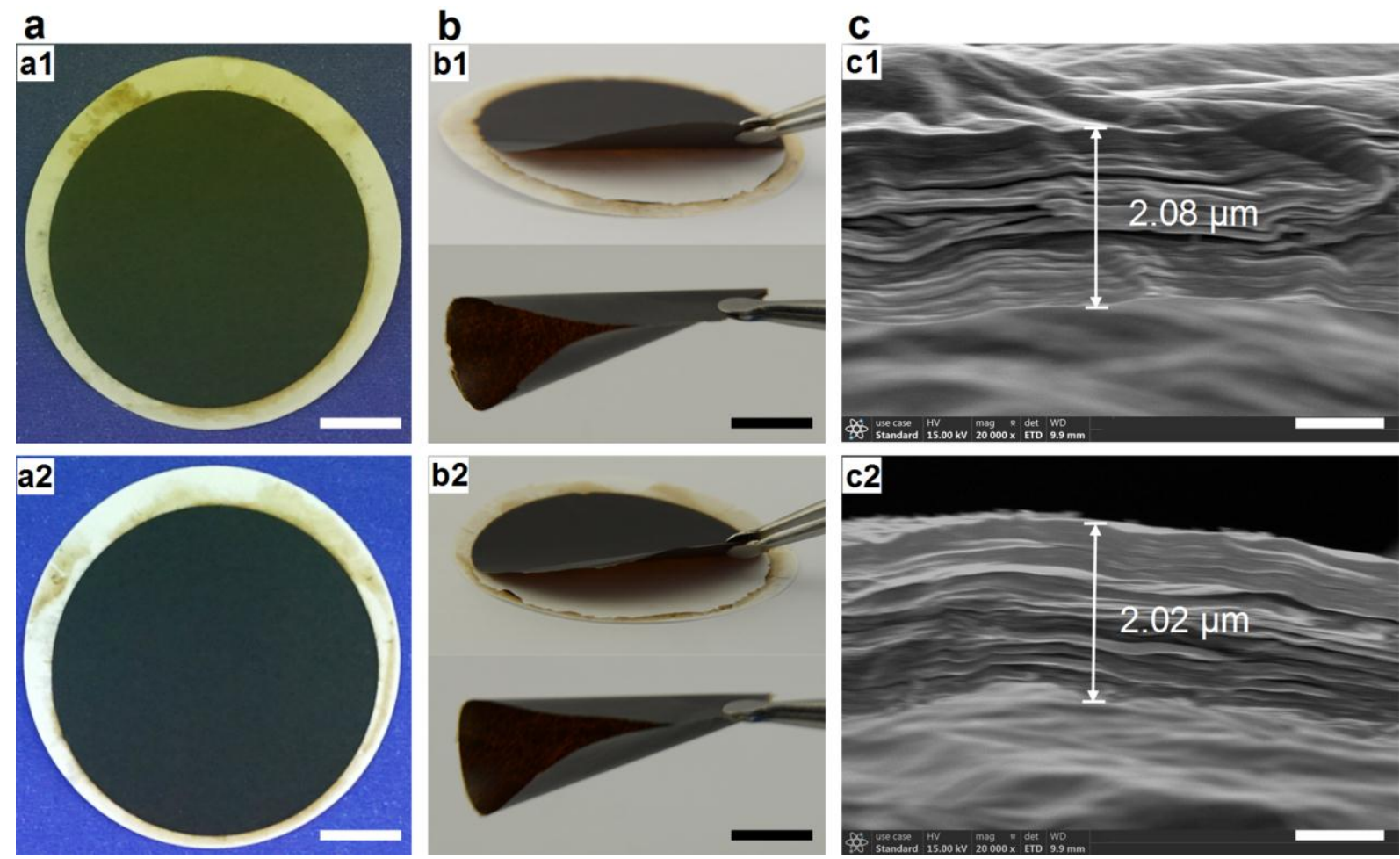

Figure S4. Photographs (a-b) and cross-sectional FESEM images (c) of GO membranes prepared via copper foil with the deposition time of $72 \mathrm{~h}$ (a1-c1) and $120 \mathrm{~h}$ (a2-c2), respectively. Scale bars are $1 \mathrm{~cm}$ in a and $\mathrm{b}$ and $1 \mu \mathrm{m}$ in $\mathrm{c}$. 

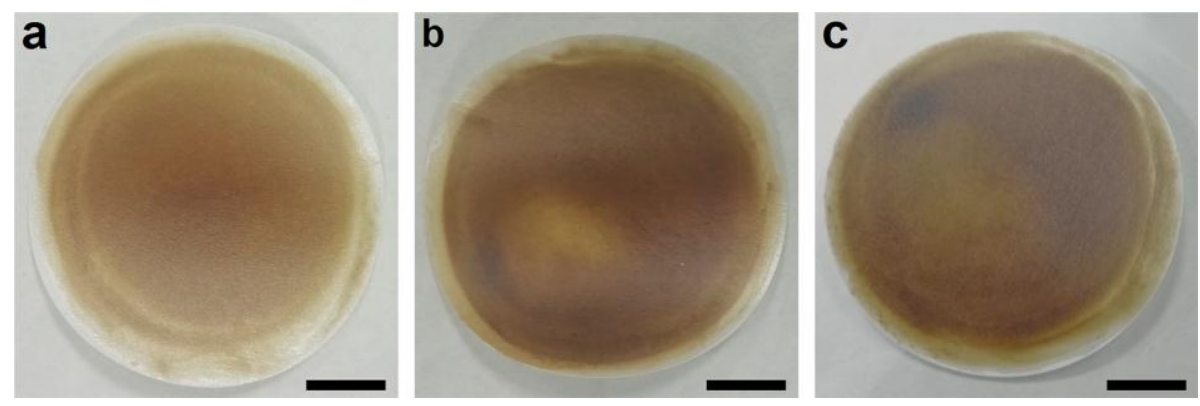

Figure S5. Photographs of pure GO membranes without crosslinked by multivalent metal cations prepared via natural deposition with the deposition time of $24 \mathrm{~h} \mathrm{(a),} 36 \mathrm{~h}$ (b) and $48 \mathrm{~h}$ (c), respectively. Scale bars are $1 \mathrm{~cm}$.
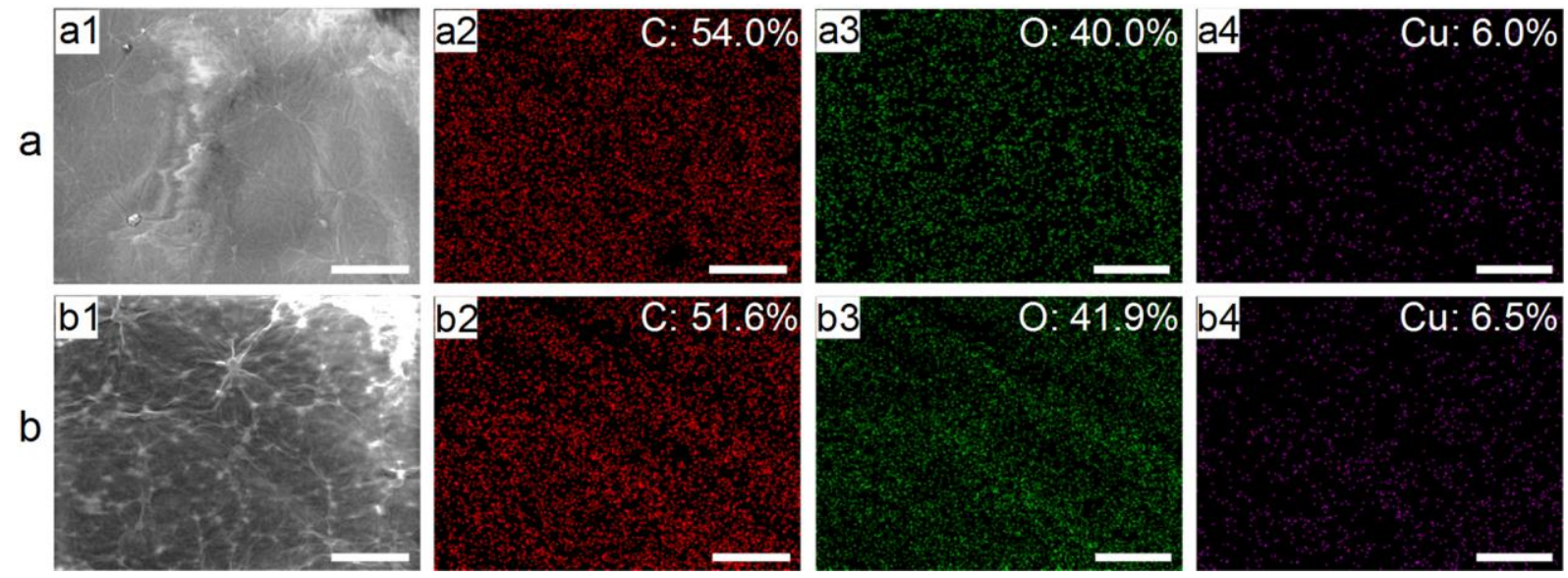

Figure S6. SEM and corresponding EDS element mapping images of the top surface (a) and bottom surface (b) of the GO-Cu-24 membrane. Scale bars are $50 \mu \mathrm{m}$. 


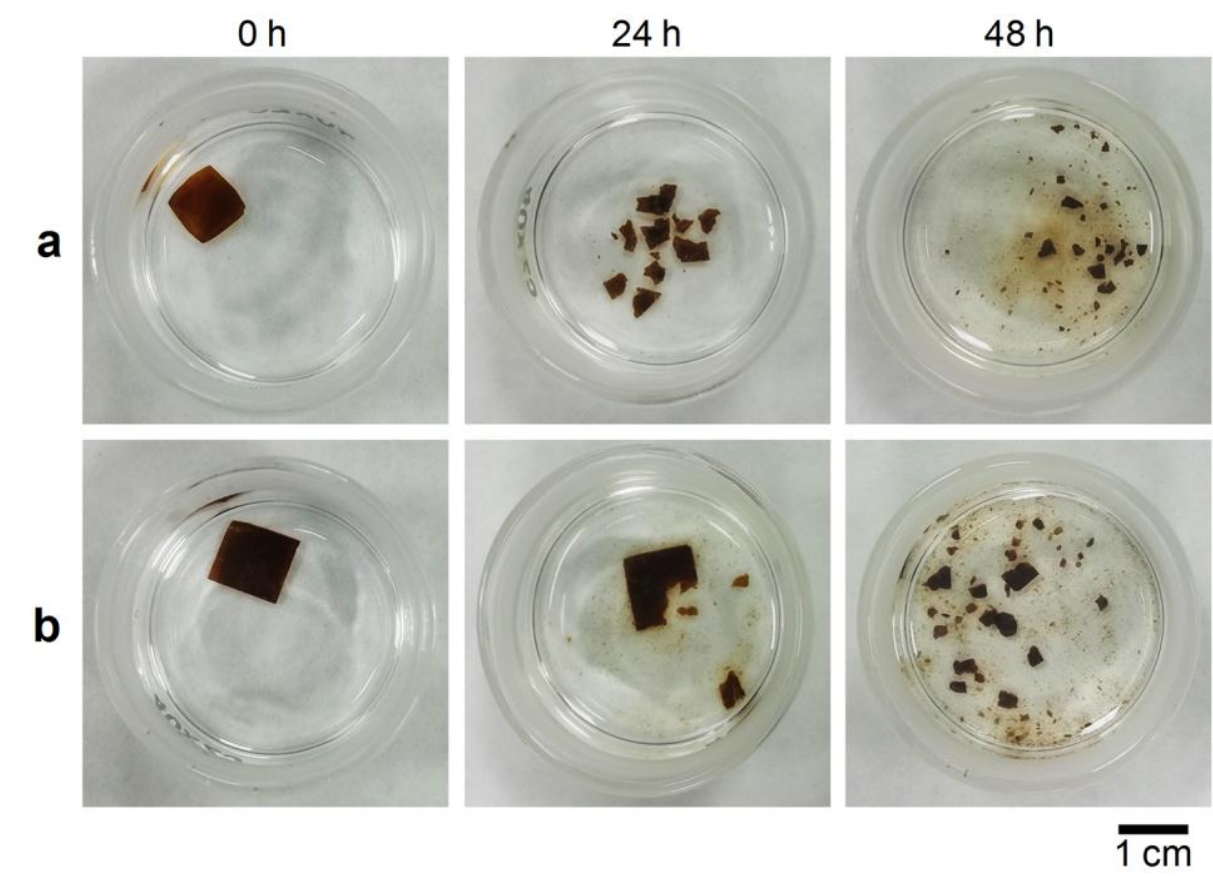

Figure S7. Stability of pure GO membranes without crosslinked by metal cations prepared via natural deposition with the deposition time of $24 \mathrm{~h}$ (a) and $48 \mathrm{~h}$ (b) after statically soaked in water.

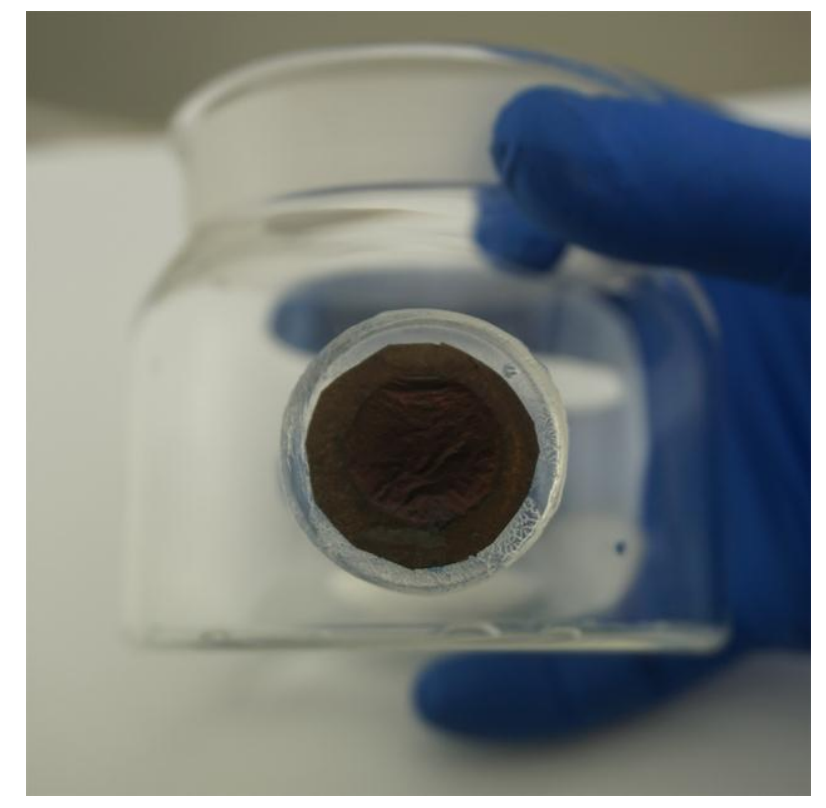

Figure S8. Photograph of GO-Cu-24 membrane is taken immediately after the separation tests of acetone and methylene blue in water. 
Table S1. Comparison of the $\mathrm{K}^{+} / \mathrm{Mg}^{2+}$ selectivities and $\mathrm{K}^{+}$permeabilities of different membranes

\begin{tabular}{|c|c|c|c|c|c|c|}
\hline Membrane type & Membrane materials & $\begin{array}{l}\text { Preparation } \\
\text { methods }\end{array}$ & $\begin{array}{c}\text { Initial ion } \\
\text { concentration } \\
\left(\mathrm{mol} \mathrm{L}^{-1}\right) \\
\end{array}$ & $\begin{array}{c}\mathrm{K}^{+} \\
\text {permeability } \\
\left(\mathrm{mol} \mathrm{m}^{-2} \mathrm{~h}^{-1}\right) \\
\end{array}$ & $\begin{array}{c}\mathrm{K}^{+} / \mathrm{Mg}^{2+} \\
\text { selectivity } \\
(-)\end{array}$ & $\begin{array}{c}\text { Data } \\
\text { source }^{b}\end{array}$ \\
\hline $\begin{array}{l}\text { Nanoporous } \\
\text { membranes }\end{array}$ & $\begin{array}{c}\text { Polyethylene } \\
\text { terephthalate (PET) }\end{array}$ & - & 1.0 & $\sim 0.00022$ & $\sim 40.0$ & Ref. 61 \\
\hline \multirow{3}{*}{$\begin{array}{c}\text { Membranes } \\
\text { stacked by two- } \\
\text { dimensional (2D) } \\
\text { nanomaterials } \\
\end{array}$} & MXene $\left(\mathrm{Ti}_{3} \mathrm{C}_{2} \mathrm{~T}_{\mathrm{x}}\right)$ & Vacuum filtration & 0.2 & $\sim 0.47$ & $\sim 5.9$ & Ref. 64 \\
\hline & Graphene oxide (GO) & Vacuum filtration & 1.0 & $\sim 0.258$ & $\sim 2.0$ & Ref. 15 \\
\hline & $\mathrm{GO}$ & Vacuum filtration & 0.1 & $\sim 0.52$ & $\sim 3.7$ & Ref. 65 \\
\hline \multirow{6}{*}{$\begin{array}{l}\text { Membranes } \\
\text { stacked by } \\
\text { modified 2D } \\
\text { nanomaterials }\end{array}$} & $\begin{array}{l}\text { GO crosslinked by } \\
\text { potassium ions }\end{array}$ & Vacuum filtration & 0.25 & $\sim 0.00048$ & $\sim 1.9$ & Ref. 17 \\
\hline & $\begin{array}{c}\text { GO covalently } \\
\text { crosslinked by } \\
\text { dicarboxylic acids, diols } \\
\text { or polyols }\end{array}$ & Vacuum filtration & 0.1 & $\sim 0.466$ & $\sim 4.2$ & Ref. 24 \\
\hline & $\begin{array}{c}\text { GO modified with } \\
\text { polyethyleneimine (PEI) }\end{array}$ & Vacuum filtration & 0.1 & $\sim 0.0582$ & $\sim 14.9$ & Ref. 60 \\
\hline & $\begin{array}{c}\text { GO crosslinked by } \\
\text { dicarboxylic acid and } \\
\text { diamine }\end{array}$ & Vacuum filtration & 0.1 & $\sim 0.0728$ & $\sim 11.8$ & Ref. 62 \\
\hline & $\begin{array}{c}\text { GO covalently } \\
\text { crosslinked by diamines }\end{array}$ & Vacuum filtration & 0.1 & $\sim 0.0932$ & $\sim 7.2$ & Ref. 63 \\
\hline & $\begin{array}{c}\text { GO crosslinked by } \\
\text { copper ions }(\mathrm{GO}-\mathrm{Cu}-24)\end{array}$ & $\begin{array}{c}\text { Natural } \\
\text { deposition }\end{array}$ & 0.1 & $\sim 0.174$ & $\sim 68.8$ & This work \\
\hline
\end{tabular}

${ }^{a}$ All the permeabilities are normalized to a $0.1 \mathrm{~mol} \mathrm{~L}^{-1}$ concentration at the feed side.

${ }^{b}$ All the reference numbers correspond to the reference numbers in the manuscript. 

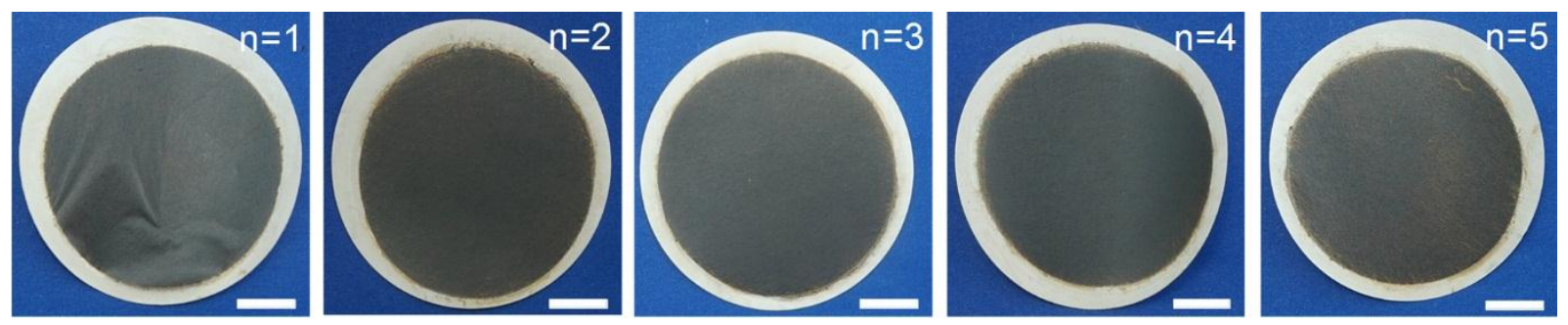

Figure S9. The photographs of GO-Cu-24 membranes prepared by reutilizing the same copper foil with the deposition time of $24 \mathrm{~h}$. The scale bars are $1 \mathrm{~cm}$.
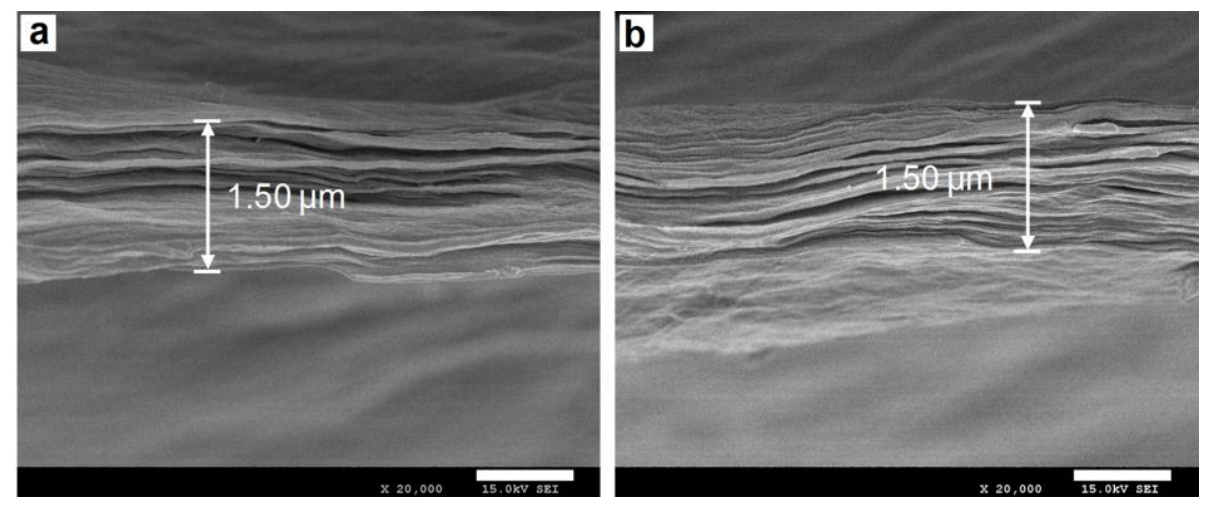

Figure S10. Cross-sectional SEM images of GO-Cu-24 membranes prepared by reutilizing the same copper foil with the deposition time of $24 \mathrm{~h}$. The repeated time is (a) $n=1$ and (b) $n=5$. Scale bars are $1 \mu \mathrm{m}$. 


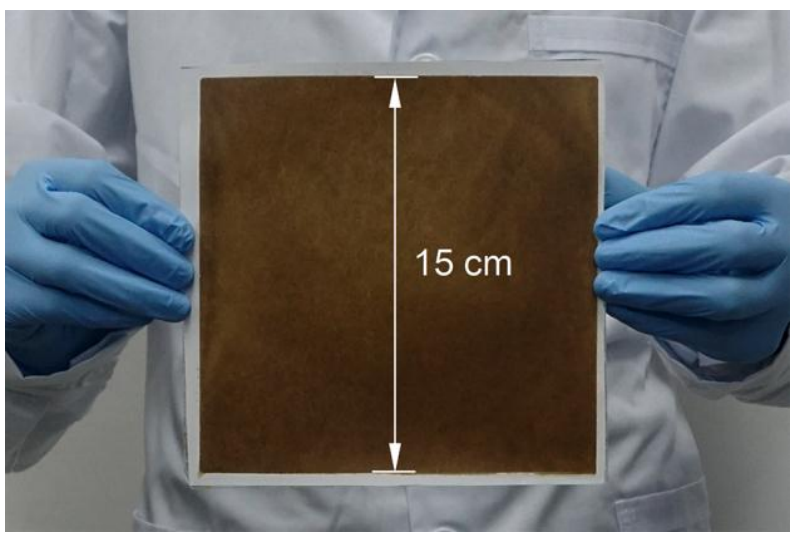

Figure S11. The photograph of a large-area GO-Cu-24 membrane with dimensions of $15 \mathrm{~cm} \times 15$ $\mathrm{cm}$.
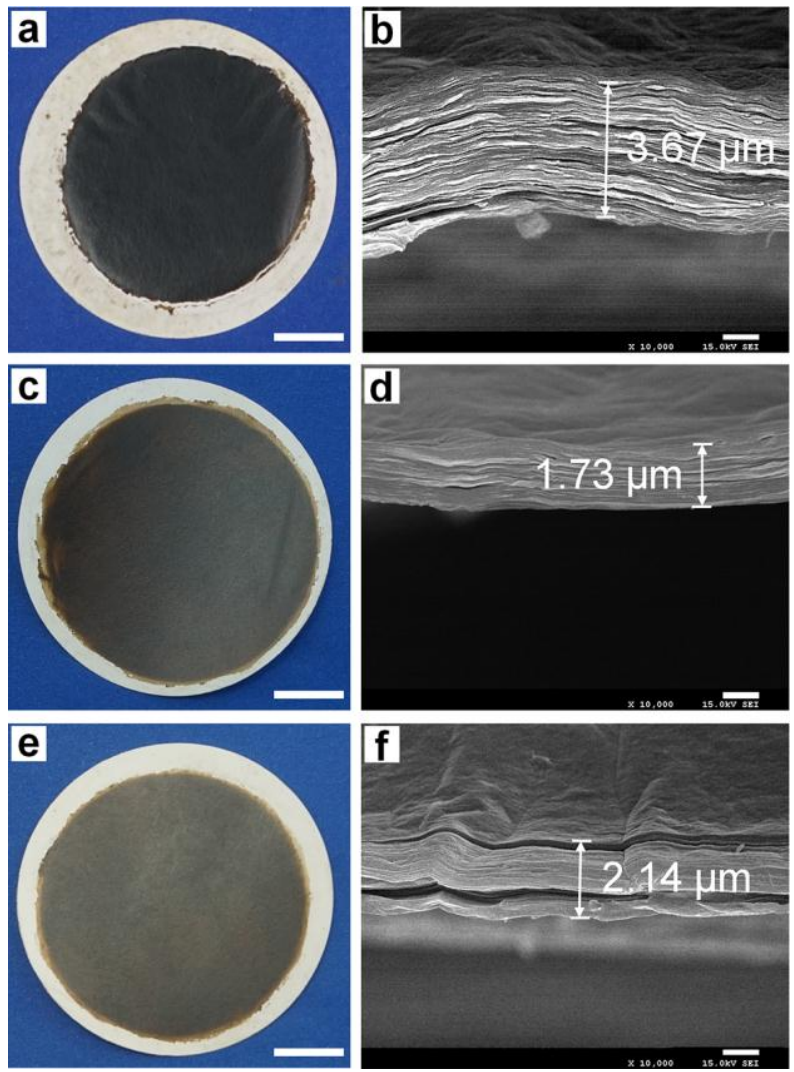

Figure S12. Photographs (a, c and e) and cross-sectional SEM images (b, d and f) of GO-M-24 membranes prepared via iron foil (a, b), nickel foil (c, d) and zinc foil (e, f) with the deposition time of $24 \mathrm{~h}$. Scale bars are $1 \mathrm{~cm}$ in a, c, and e, and $1 \mu \mathrm{m}$ in b, $\mathrm{d}$ and $\mathrm{f}$. 
Table S2. Radii of metal cations in crystal $^{59}$ a

\begin{tabular}{cc}
\hline Metal cation species & Metal cation radius in crystal $(\AA)$ \\
\hline $\mathrm{Cu}^{2+}$ & 0.72 \\
$\mathrm{Fe}^{3+}$ & 0.60 \\
$\mathrm{Ni}^{2+}$ & 0.70 \\
$\mathrm{Zn}^{2+}$ & 0.74 \\
\hline
\end{tabular}

a The reference number corresponds to the reference number in the manuscript.

Table S3. The XPS results of GO membranes prepared via iron foil, nickel foil and zinc foil with the deposition time of $24 \mathrm{~h}$.

\begin{tabular}{cccccc}
\hline Sample & C (at.\%) & N (at.\%) & O (at.\%) & M (at.\%) $^{\text {a }}$ & M $^{\mathrm{a}}$ (wt.\%) \\
\hline GO-Fe-24 & 66.50 & 0.49 & 31.83 & 1.19 & 4.81 \\
GO-Ni-24 & 66.61 & 0.40 & 32.30 & 0.69 & 2.97 \\
GO-Zn-24 & 64.97 & 0.62 & 33.77 & 0.63 & 3.01 \\
\hline
\end{tabular}

a represents the various metal cations. 

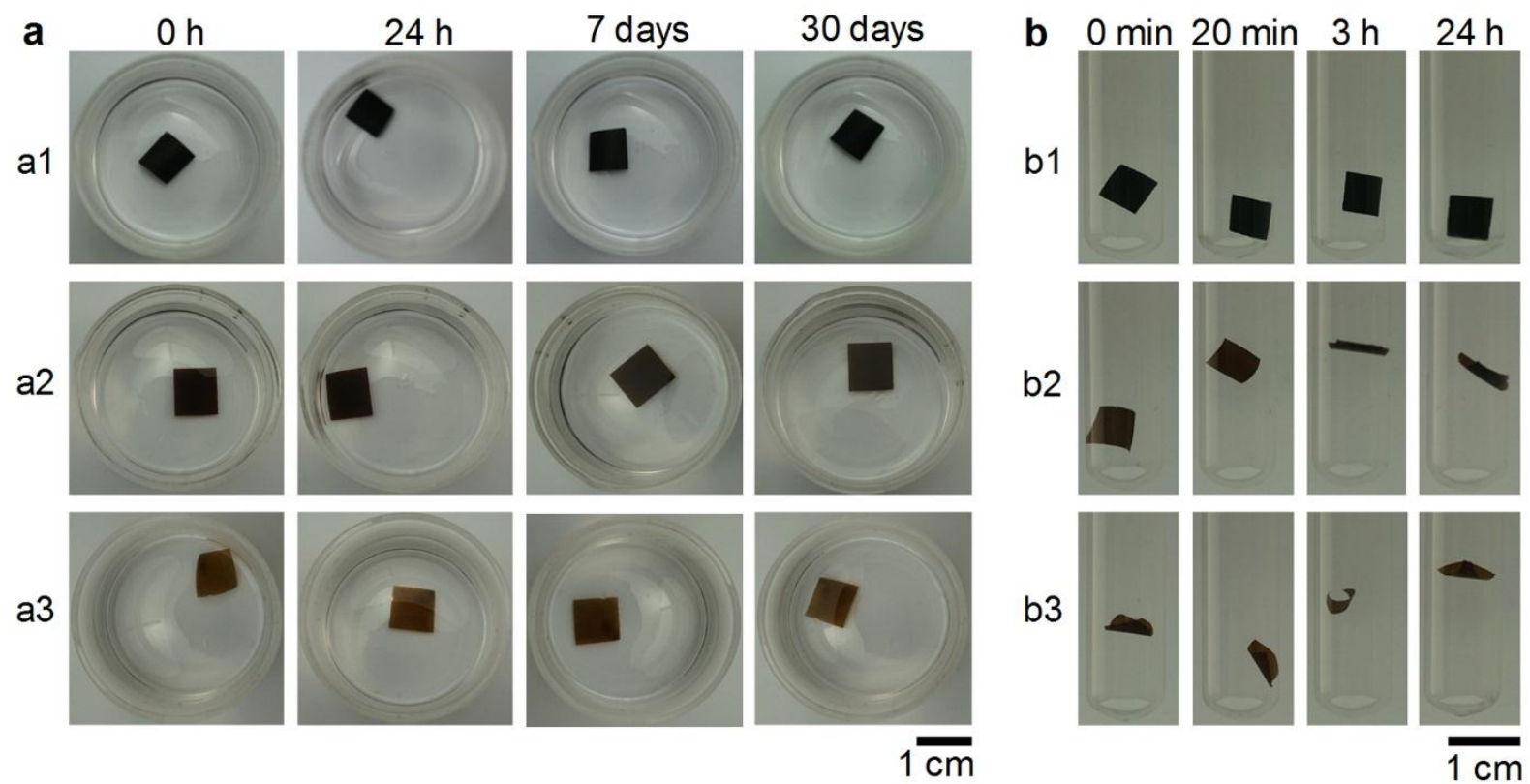

Figure S13. Stability in ethanol of GO-M-24 membranes prepared via iron foil (a1, b1), nickel foil (a2, b2) and zinc foil (a3, b3) with the deposition time of 24 after (a) statically soaked in ethanol for different time; (b) stirred for several seconds with a IKA vortex mixer at $2800 \mathrm{rpm}$ after soaked in ethanol for different time. 

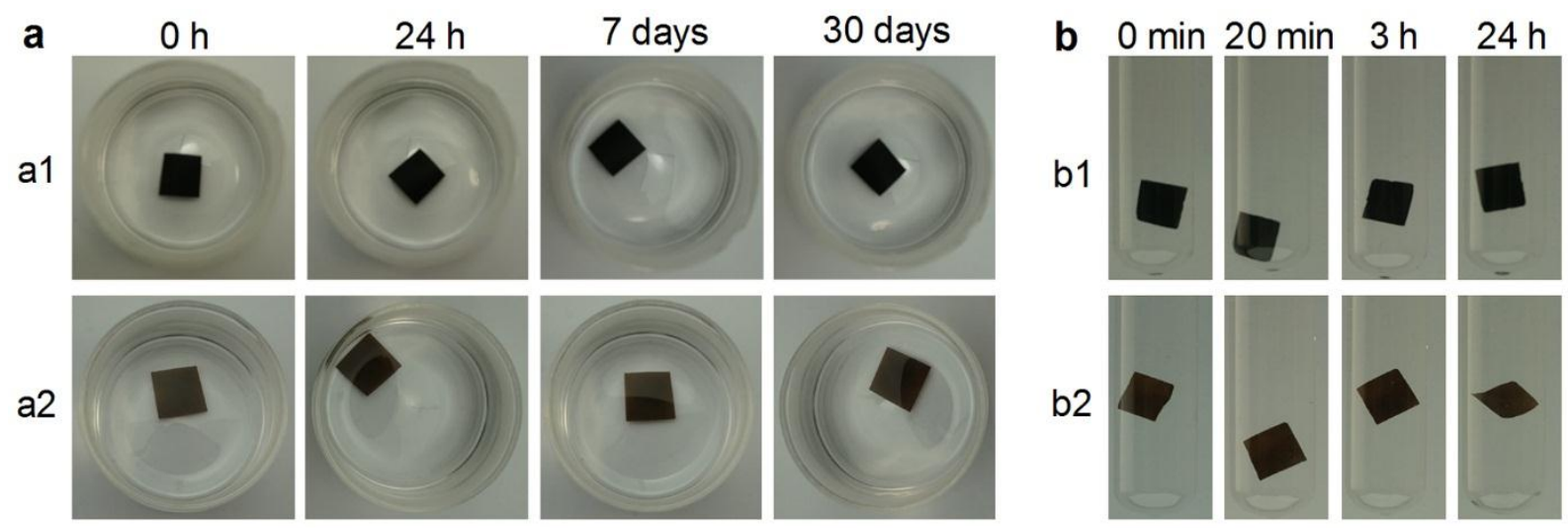

a3
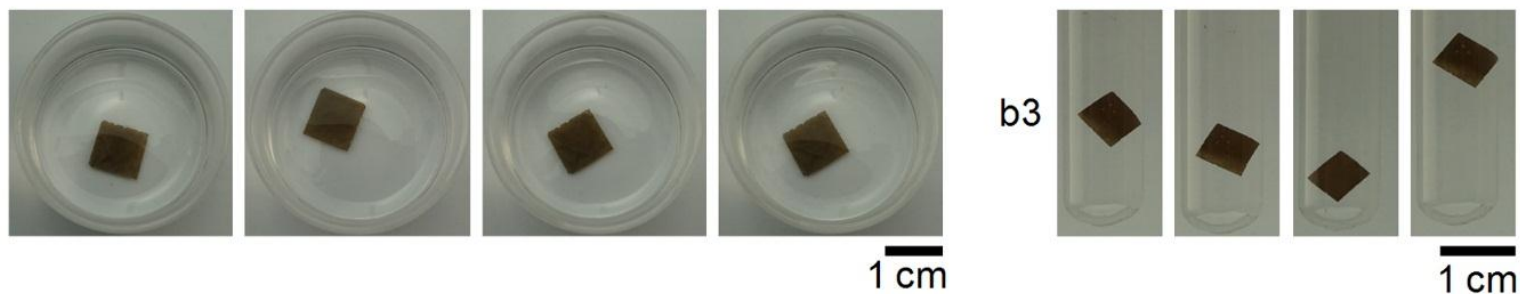

Figure S14. Stability in water of GO-M-24 membranes prepared via iron foil (a1, b1), nickel foil $(a 2, b 2)$ and zinc foil (a3, b3) with the deposition time of 24 after (a) statically soaked in water for different time; (b) stirred for several seconds with a IKA vortex mixer at $2800 \mathrm{rpm}$ after soaked in water for different time. 

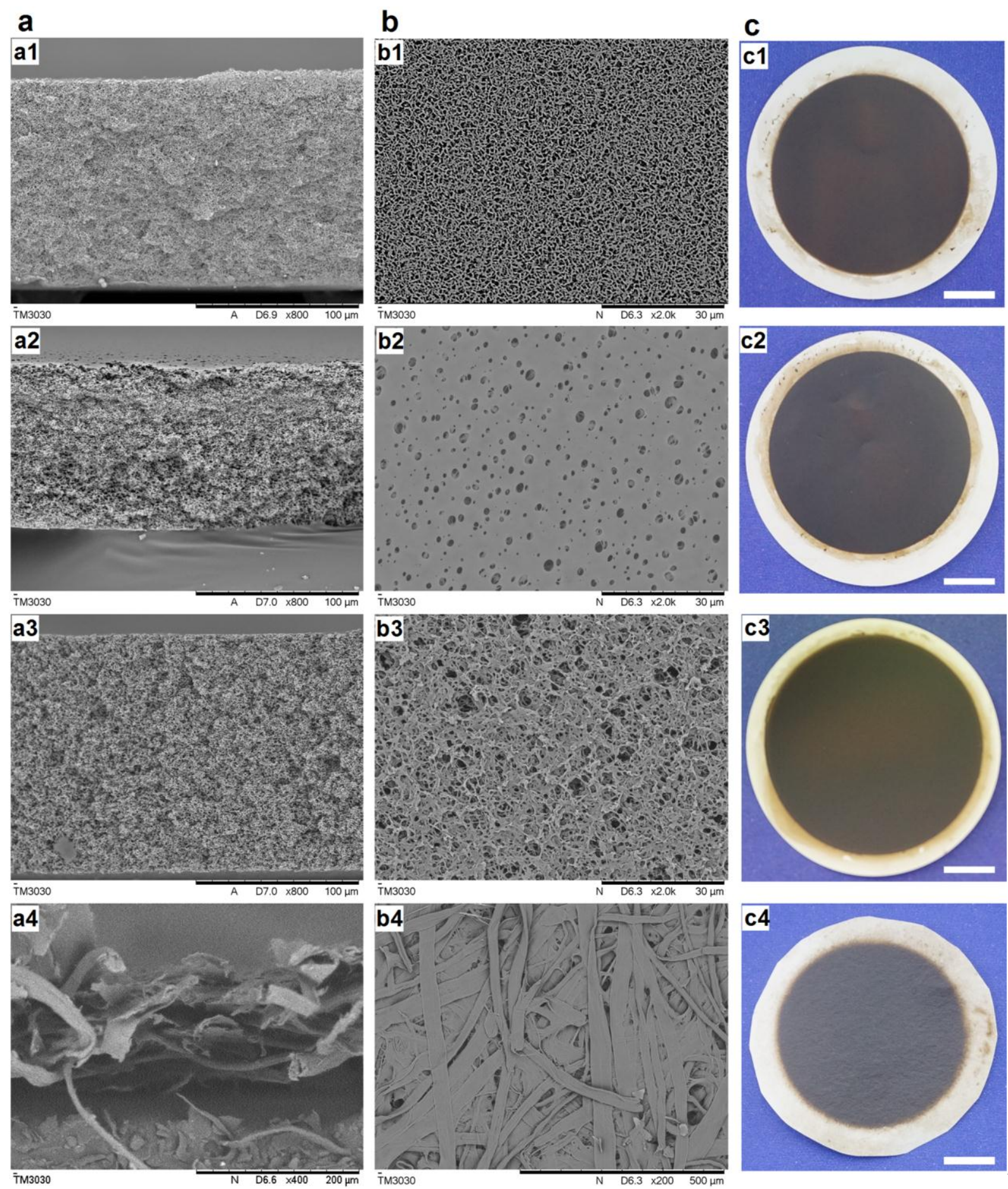

Fig

ure S15. SEM images of cross-sectional (a) and surface (b) views of PVDF membrane (a1-b1), PES membrane (a2-b2), nylon membrane (a3-b3) and ordinary filter paper (a4-b4), and photographs (c) of corresponding GO-Cu-24 membranes prepared via copper foil and these 
substrate membranes with the deposition time of $24 \mathrm{~h}$. Scale bars are $100 \mu \mathrm{m}$ in (a1-a3), $30 \mu \mathrm{m}$ in (b1-b3), $200 \mu \mathrm{m}$ in a4, $500 \mu \mathrm{m}$ in b4, and $1 \mathrm{~cm}$ in c, respectively. 